\title{
DNR and the Use of Blended Learning Methodology in German Police Education
}

\author{
Melanie Brand and Kirsten Mahlke \\ University of Konstanz, Germany \\ Kontakt-dnr@uni-konstanz.de
}

\begin{abstract}
The article purposes to examine the opportunities and challenges of introducing blended learning modules for the facilitation of reflexive learning within the police. It will discuss the conceptualization of 'DNR' (Death Notification with Responsibility), a blended learning course for police students in Germany which focuses on the administering of death notifications according to both professional and legal requirements, reacting flexibly and compassionately to the needs of the bereaved. DNR has two main aims: (1) the imparting of crucial factual knowledge, and (2) the creation of opportunities for intensified reflexive and participatory learning. The concept combines classroom-based learning with e-learning modules. E-learning components allow students to engage with the sensitive issue of death notification at their own pace; when and where they feel comfortable. The overall course objectives are complicated by the police's hierarchical organizational structure, as well as the preference of experience-based, on-the-job learning, and a general mistrust towards 'academization' of police education in Germany.
\end{abstract}

Keywords: Blended learning, death notification, police education.

\section{Introduction}

Imparting news of a death to next of kin is a stressful and delicate task falling to medical and lawenforcement professions. Research indicates the need for further training on death notification as a form of professionalization (Douglas et al. 2013, Nordström 2011). Despite classroom-based training, availability of best-practice recommendations and step-by-step guidelines on the process of death notification, police officers in Germany still feel ill-prepared for delivering notifications (cf. Fresen 2016). Currently, no standardized police training for such procedure is available in Germany.

The experiences of bereaved individuals who have received a death notification add urgency to the need for deeper engagement with death-related grief in police education. A study conducted by the German police with the local chaplaincy revealed that the bereaved felt excluded from legal process and police procedure pertaining to the death of their loved one, many complaining about a lack of information and support (Trappe 2001). These impressions were substantiated through exploratory conversations with both police officers and bereaved parents during the planning phase of DNR. These demonstrated the still-pressing need of adequate death notification training. 
Reflecting on the challenges of communicating an unexpected and often violent death, the article discusses the blended learning module 'DNR - Death Notification with Responsibility'. Funded by the European Research Council (ERC), the training module is currently being developed by a team of cultural scientists and social anthropologists at the University of Konstanz in partnership with the police. Given the delicacy of the issue, how can death notification be formally taught?

Put simply, ideal training should encompass both 'hard facts' and 'soft skills' (cf. De Leo et al. 2015, Trappe 2001). The concept of DNR follows the notion that new educational approaches are necessary to facilitate experience-based learning and reflexive learning within the peer group, whereby communicative competencies in work-based emotional engagement may be strengthened. The blended learning course will enable police to prepare for death notification delivery through a multi-layered approach, integrating classroom education and group-work as well as interactive e-learning components on a range of topics related to death and communication in sensitive situations.

\section{Death Notification and Police in Germany}

\subsection{Telling the Untellable}

In Germany, no specific law or regulation exists that clearly identifies the delivery of death notifications as a responsibility of law enforcement. In terms of prevention, the protection of individual or public safety and the protection of victims' rights, death notifications clearly fall into the realm of police duty (see Fresen 2016, Trappe 2001). The importance of victims' rights has recently been emphasized on EU-level through Directive 2012/29 that specifically highlights victims' rights to information.

There is literary consensus indicating that the way a death notification is conveyed drastically impacts the grieving process (cf. De Leo et al 2015, Trappe 2001). Psychological disorders such as depression, listlessness and phobia are among the long-lasting effects which may in turn contribute to likelihoods such as suicide if the delicate initial bereavement is handled with careless or uninformed communication. At the same time, bearing the news which causes a person's world to collapse, and witnessing the emotional aftermath, has the potential to result in psychological complications. By communicating a death, even the death of a stranger, one's own mortality is implicated. Confronting one's feelings about death and mortality seems likely to reduce a general discomfort in facing the sensitive subject. Incorporating questions concerning 'emotion work' (Szymenderski 2014) into the blended learning module provides an impulse to scrutinize the meaning and importance of processes that may seem at first to belong to the realm of tacit knowledge and informal learning in the workplace.

\subsection{Police Education in Germany}

It is most important to note that police education in Germany is organized federally with the respective curricula of the sixteen federal states varying widely. Today, due to the educational reform known as the 
Bologna process, higher law-enforcement students graduate with a Bachelor of Arts diploma. The content of the three-year study is manifold. However, the proliferation of more 'theoretical' topics is often met with skepticism, even evoking fears of an academization of the otherwise hands-on police training (see Kersten 2013: 57).

At university-level, death notification training usually forms a feature of ethics, psychology or communication training. Death notification training is most often provided by chaplains, but in some federal states may fall to ethics professors. In Baden-Württemberg, students of the Bachelor program preparing them for positions in higher law-enforcement receive six hours of training on death notification as part of a module on ethics. This includes two hours on psychological aspects of grief, two hours of group work including roleplays, one hour's reflection on the experiences simulated by the roleplays and one hour on intercultural aspects of death and grief.

We understand DNR as a tool that may be fully or partly integrated into the existing learning environment. Preference for 'learning on the job' over theoretical discussion indicates the need for adequate educational methodologies. For example, DNR includes a roleplaying unit during which students gain valuable experience through simulation. By outsourcing knowledge dissemination to the course's online component, the relatively limited classroom-based learning can be productively devoted to participatory and experienced-based forms of learning.

To summarize: Death notifications present a highly sensitive and challenging task for police officers which requires specific factual, legal and bureaucratic knowledge as well as interpersonal skills, reflective abilities and self-care competencies. If ill-prepared to deliver appropriately, notifications result in negative consequences for the bereaved by drastically complicating the grieving process. Additionally, the task presents a risk to the emotional and psychological wellbeing of officers.

\section{Death Notifications: Preparing Police Students}

Relevant literature on death notification, trauma elicited by death encounters, and the needs of next of kin in cases of sudden, violent death is readily available. However, there remains a lack of comprehensively informed, systematically established and didactically tailored teaching material on the subject, and on how it may be applied in practice. Police students in the second decade of the 21 st century are digital natives and require educational material corresponding to their learning habitats. Blending face-to-face classroom training with e-learning allows for flexibility in modalities and multifaceted medial representation of diverse learning content. Blended learning provides students with both the possibility to reflect on sensitive issues at their own pace and in their preferred environment, and the opportunity to interact with peers and facilitators in a group setting.

The blended learning course follows the idea of the 'flipped classroom' meaning that classroom sessions are used for interactive and participatory, experienced-based and dialogical learning instead of 
teacher-centered knowledge dissemination. Lectures and sharing of factual knowledge is outsourced to DNR's e-learning components. In this way, the blended learning module makes the most of the limited time and space available. Furthermore, blended learning enables a "community of inquiry" that, according to Garrison and Kanuka (2004: 97), consists of cognitive and social elements as well as teaching presence. Such communities of inquiry strengthen students' commitment to the joint learning project (ibid.: 99). In order to encourage the community building process, DNR follows Garrison and Kanuka's suggestion to start with a face-to-face session and proceed with e-learning modules afterwards.

Before the first session, students will be able to log into the e-learning platform in order to familiarize themselves with the medium. A video will inform them about the importance of death notification training and the responsibility that comes with the task. In another sequence, the overall structure of the e-learning component is explained. The sequential structure of the e-learning component follows the typical course of police action, leading students through several phases of the notification process. Already implicated by the structure, a thought-cue is given: death notifications are not a 'once-off' but must be understood as the beginning of a process that continues long after the doorbell is rung and a message is conveyed.

In order to prepare for the first face-to-face session, participants watch a comical video of a worstcase notification scenario and are encouraged to reflect and discuss. The aim of the first session is to engage in team- and trust-building activities. Through various exercises, participants reflect on their own experiences with death, discuss society's view of death and the role of death communication in a police officer's profession. Questions encouraging intense reflection will be posed, for example: "If something tragic was to happen to you, how would you like your next of kin to be informed?" Ideally, a person who has received a death notification in the past is invited to the session. This would allow students to engage with a 'survivor', ask questions and listen to first-hand accounts, enabling the essential change of perspective. After the first face-to-face session, DNR's e-learning phase will commence. The following outlines the basic content of each of the six chapters:

\section{Coordination of Police Operation}

During first contact via an emergency call, basic information about what has happened, where and to whom is transmitted to police. On this basis, deployment is coordinated and officers sent to the location. Already at this stage, information can be identified that might become important during notification, i.e. Who placed the emergency call? Are there witnesses to the incident?

\section{Arrival at the Scene and First Investigations}

Officers' responsibilities and involvement is defined and the chain of information coordinated. During first investigations and collection of data, officers must be aware that information not relevant to criminal investigations may still be crucial to notification. These must be noted.

\section{Collecting Background Information}


Officers responsible for notifying next of kin must collect detailed information about the incident, who was involved and who needs to be notified. If available, information about family structures must be considered. In the case of divorced parents, for example, cooperation with another police district might be necessary to ensure a personal notification of next of kin through appropriate local authorities.

\section{Preparing the Notification}

As notifications are always handled by two officers, roles must be delegated. Based on the specific details of the situation and availability, chaplains or crisis intervention experts must be consulted. Officers must engage in emotion work and attune to the imminent notification.

\section{Conveying the Death Notification}

As early as possible, the message must be conveyed in clear, concise language. Officers need to react to the specifics of the situation, answer questions, provide basic emotional support and provide crucial information such as contact details. In terms of prevention, and the protection of victims, officers must wait until a third party is present. Emotion work and debriefing ensues.

\section{Follow up and Completion}

Police officers function as gatekeepers and are in a position to provide the bereaved with access to (a) further information about the incident, (b) ongoing procedure, (c) possessions carried by their loved one at the time of death, (d) prosecution, (e) other parties involved such as witnesses and first-aiders.

All chapters are structured following the same logic. Eight categories, visually represented as tiles, organize the learning contents: Chapter Introduction (overview of contents, learning objectives, duration), Knowledge Dissemination (lectures, texts, animations), Spheres of Responsibility (legal aspects, policies, discretionary powers), Video Element (interview, film), Voices (perspectives of bereaved, first-aid responders, chaplains), Further Material (database including relevant songs, books, movies, articles), Tools (brochures, check lists) and Test/Quiz (checking learning progress via multiplechoice questions).

One of DNR's most important features constitutes the category, Voices. Here, students are provided with first-hand accounts from individuals who have received a death notification, willing to share their experience. The students will also find expert accounts from people engaged in 'death work'. This includes chaplains, medical doctors, nurses, police officers, pathologists and morticians. Depending on interviewees' preferences, their accounts are given as text, audio or video allowing different degrees of anonymization. Voices offers students a change of perspective, an opportunity for intense reflection on the meanings and consequences of death in context. The e-learning component also features an FAQ section and forum in which students may engage and share.

After the completion of the e-learning phase, a second classroom-based session will follow during which the online modules are discussed. The session will include experience-based learning via roleplaying. Course facilitators will receive scripts providing the basis for learning activity. The role of next of kin may be played by professional actors, but if not possible, by the course facilitator or students themselves. The benefit of simulation exercises in death notification training has been highlighted in different contexts (cf. Nordström et al. 2011). 
DNR will be prototyped in the police academy of Duisburg/Germany where it will be integrated into a semester-based course on ethics and social communication skills. Students as well as facilitators will receive evaluation forms in which to rate each course component by comprehensibility, usability, relevance and sophistication.

\section{Discussion}

Put simply, blended learning is "the thoughtful integration of classroom face-to-face learning experiences with online learning experiences" (Garrison \& Kanuka 2004: 96). In DNR, contents of classroom-based learning and e-learning are geared to each other. During roleplays, students get to apply and to reflect upon their acquired knowledge in a concrete experiential situation. DNR draws on a student-centered methodology with the learning process being supported by the teacher and peers. In contrast to Cope and Kalantzis (2016:1) who state that „technology is pedagogically neutral”, Garrison and Kanuka (2004: 97) assume specific pedagogical qualities implicated in online learning like encouraging reflection and precision of expression. By implementing a moderated forum in which facilitators give impulses for reflection, DNR encourages students to formulate their thoughts and attitudes and to share them with other participants.

As the conceptual review has shown, blended learning methodologies offer promising opportunities to integrate reflexive, experiential and participatory learning into the environment of police education. In the face of various challenges, it is the aim of DNR to train police officers for professional death notification delivery and, in so doing, prevent both the re-victimization of the bereaved and potential trauma suffered by the officers themselves.

\section{References}

Cope, B., \& Kalantzis, M.: E-learning Ecologies. Principles for New Learning and Assessment. Taylor \& Francis, New York (2017).

Douglas, L., Cheskes, S., Feldman, M., \& Ratnapalan, S.: Death Notification Education for Paramedics. Past, Present and Future Directions. Journal of Paramedic Practice, 5(3), 152-159 (2013).

De Leo, D., Anile, C., Ziliotto, A.: Violent Deaths and Traumatic Bereavement: The Importance of Appropriate Death Notification.Humanities, 4(4), 702-713 (2015).

Fresen, L.: Überbringen von Todesnachrichten als Herausforderung und kulturübergreifende

Aufgabe für die Polizei. BA Thesis, Police Academy Niedersachsen (2016).

Garrison, D. R., \& Kanuka, H.: Blended learning: Uncovering its Transformative Potential in Higher Education. The Internet and Higher Education, 7(2), 95-105 (2004).

Nordström A., Fjellman-Wiklund A., Grysell T.: Drama as a Pedagogical Tool for Practicing Death Notification-Experiences from Swedish Medical Students. BMC Medical Education, 11 (1), 74.

Szymenderski, P.: Gefühlsarbeit im Polizeidienst. Wie Polizeibedienstete die emotionalen Anforderungen ihres Berufs bewältigen. transcript, Bielefeld (2012). 
Trappe, T.: Die Unwirklichkeit des Todes Erfahrungen und Überlegungen bei der Begleitung von Verkehrsunfallopfern und ihren Angehörigen. Psychotraumatologie2(3):17 (2011).

Kersten, J., Ansgar B.: Police Science in Germany. History and New Perspectives. Journal of Police Studies/Cahiers Politiestudies 1.1 (2013). 